\title{
miR-320-3p is involved in morphine pre-conditioning to protect rat cardiomyocytes from ischemia/reperfusion injury through targeting Akt3
}

\author{
LAN CAO $^{1}$ and SHIJUN CHAI ${ }^{2}$ \\ Departments of ${ }^{1}$ Anesthesiology and ${ }^{2}$ Orthopedics, Tiantai People's Hospital of Zhejiang Province, \\ Tiantai, Zhejiang 317200 , P.R. China
}

Received November 21, 2019; Accepted April 16, 2020

DOI: $10.3892 / \mathrm{mmr} .2020 .11190$

\begin{abstract}
Morphine pre-conditioning (MPC) can significantly reduce myocardial ischemic injury and inhibit cardiomyocyte apoptosis, but the underlying mechanism still remains unclear. The aim of the present study was to investigate the protective mechanism of MPC in myocardial hypoxia/reoxygenation $(\mathrm{H} / \mathrm{R})$ injury at the microRNA ( $\mathrm{miR})$ level. H9c2 cells were used as a model of H/R and subjected to morphine pre-treatment. The protective effects of MPC on H/R injury in cardiomyocytes were evaluated using MTT and colorimetric assay, as well as flow cytometry. In addition, reverse transcription-quantitative PCR, western blotting and dual-luciferase reporter assay experiments were performed to determine the relationship between MPC, miR-320-3p and $\mathrm{Akt} 3$, and their effects on $\mathrm{H} / \mathrm{R}$ injury. The present study demonstrated that MPC enhanced cell activity, decreased LDH content, and reduced apoptosis in rat cardiomyocytes, suggesting that MPC could protect these cells from H/R injury. Moreover, MPC partially reversed the increase in miR-320-3p expression and the decrease in Akt3 levels caused by H/R injury. Inhibition of miR-320-3p expression also attenuated the effects of H/R on cardiomyocyte activity, LDH content and apoptosis. Furthermore, Akt3 was predicted to be a target gene of miR-320-3p, and overexpression of miR-320-3p inhibited the expression of Akt3, blocking the protective effects of MPC on the cells. The current findings revealed that MPC could protect cardiomyocytes from H/R damage through targeting miR-320-3p to regulate the PI3K/Akt3 signaling pathway.
\end{abstract}

Correspondence to: Dr Shijun Chai, Department of Orthopedics, Tiantai People's Hospital of Zhejiang Province, 1 Kangning Middle Road, Shifeng Street, Tiantai, Zhejiang 317200, P.R. China E-mail: chshjun_sjun@163.com

Key words: morphine pre-conditioning, Akt3, myocardial hypoxia/reoxygenation injury, miR-320-3p, apoptosis

\section{Introduction}

Myocardial ischemia/reperfusion injury (MI/RI) refers to rapid tissue damage caused by the recovery of blood flow from myocardial cells following ischemia (1). MI/RI is a common complication during the perioperative period of cardiac and macrovascular surgeries that can lead to the aggravation of myocardial damage and seriously affect the recovery of postoperative cardiac function (2). Cardiomyocyte hypoxia/reoxygenation (H/R) injury can be used to mimic myocardial ischemia/reperfusion in vitro $(3,4)$. Morphine is a widely used analgesic in cardiac and macrovascular anesthesia $(5,6)$. Compared with ischemic pre-conditioning, morphine could be conveniently and easily administered and cause less trauma to patients (7). Previous studies demonstrated that morphine pre-conditioning (MPC) significantly reduced myocardial ischemic injury and inhibited cardiomyocyte apoptosis, although the mechanism remains unclear $(8,9)$.

MicroRNAs (miRNAs/miRs) are a class of endogenous, single-stranded, non-coding RNAs that regulate multiple biological processes such as cell proliferation, differentiation and apoptosis (10). Cardiomyocyte apoptosis is an important characteristic of MI/RI (11). Accumulating evidence indicates that miRNAs can regulate apoptosis of cardiomyocytes through their target genes and downstream signaling pathways (12). For example, Dong et al (13) suggested that miR-21 could inhibit ischemia-induced apoptosis by studying acute myocardial infarction in rats. Cheng et al (14) demonstrated that miR-21 also protected cardiomyocytes from hydrogen peroxide-induced damage by regulating programmed cell death 4. Moreover, miR-320 was also implicated in the regulation of myocardial ischemia/reperfusion injury, and miR-320 upregulation could promote cardiomyocyte apoptosis (15). Additionally, miR-320 has multiple functions in different environments (16), and its expression level is closely related to tumor migration and invasion. Indeed, overexpression of miR-320 is associated with high risk of metastasis and poor prognosis (17).

Previous studies demonstrated that 5'-adenosine monophosphate-activated protein kinase (AMPK) could ameliorate myocardial ischemia through the regulation of oxidative stress $(18,19)$, autophagy $(20,21)$ and apoptosis (22) 
in cardiomyocytes. Moreover, AMPK exerts its protective effects with other molecules that may have crosstalk with each other against myocardial ischemia, for example, mesenchymal stem cell (MSC)-derived exosomes could reduce MI/RI by inducing cardiomyocyte autophagy via AMPK/mTOR and Akt/mTOR pathways $(21,23,24)$. Sun et al $(25)$ demonstrated that dexmedetomidine protected mice against MI/RI by activating the AMPK/phosphatidylinositol-4,5-bisphosphate 3-kinase (PI3K)/Akt/endothelial nitric oxide synthase pathway. $\mathrm{PI} 3 \mathrm{~K} / \mathrm{Akt}$ signaling is an important signaling pathway associated with many diseases, including cancer and neurological diseases (26). Akt kinase consists of three subtypes, Aktl, Akt 2 and $\mathrm{Akt} 3$, which are the key factors downstream of the PI3K signaling pathway that regulate cell proliferation, apoptosis and metastasis (27). Previous studies indicated that activation of the PI3K-Akt signaling pathway protected the heart from reperfusion injury (28). However, whether morphine pre-conditioning participates in myocardial $\mathrm{H} / \mathrm{R}$ injury through the regulation of miR-320-3p and the PI3K/Akt signaling pathway is not fully understood. Therefore, the current study examined the myocardial protection mechanism of MPC following at the miRNA level, and aimed to elucidate the relationship between MPC, miR-320-3p and the PI3K/Akt signaling pathway in the regulation of $H / R$ injury of cardiomyocytes.

\section{Materials and methods}

Cell culture. H9c2 cells (cat. no. CRL-1446) were obtained from the American Type Culture Collection and divided into four groups: i) Control, ii) MPC, iii) $\mathrm{H} / \mathrm{R}$, and iv) $\mathrm{MPC}+\mathrm{H} / \mathrm{R}$. Cells from the control group were cultured in DMEM/F-12 containing $10 \% \mathrm{FBS}$, and $1 \%$ penicillin/streptomycin at $37^{\circ} \mathrm{C}$ with $5 \% \mathrm{CO}_{2}$ (all from Thermo Fisher Scientific, Inc.). After one day of culture, the original medium was discarded, and the cells were washed once or twice with PBS, then resuspended in $5 \mathrm{ml}$ fresh DMEM/F-12 medium and returned to the $\mathrm{CO}_{2}$ incubator. The cells were passaged when grown to 80 to $90 \%$ confluence. In the MPC group, cells were cultured normally following a 10 -min treatment with $1 \mu \mathrm{M}$ morphine (cat. no. 121206-2; Northeast Pharmaceutical Group Co., Ltd.). In the H/R group, DMEM/F12 medium containing $10 \%$ serum was replaced by anoxic solution (i.e., glucose-free and serum-free medium containing $2.3 \mathrm{mM} \mathrm{CaCl}_{2}, 5.6 \mathrm{mM} \mathrm{KCl}$, $154 \mathrm{mM} \mathrm{NaCl}, 5 \mathrm{mM}$ Hepes, and $3.6 \mathrm{mM} \mathrm{NaHCO}$; $\mathrm{pH}$ 7.4). The culture plate was maintained in anoxic chamber for $5 \mathrm{~h}$ at $37^{\circ} \mathrm{C}$, and then reoxygenation for $1 \mathrm{~h}$ in DMEM/F12 medium containing $10 \%$ serum under a humidified atmosphere $(95 \%$ air and $5 \% \mathrm{CO}_{2}$ ) at $37^{\circ} \mathrm{C}$. For the MPC $+\mathrm{H} / \mathrm{R}$ group, the cells were treated with $1 \mu \mathrm{M}$ morphine in serum-free DMEM/F12 for $10 \mathrm{~min}$. Following the treatment, serum-free DMEM/F12 was replaced by DMEM/F12 medium containing $10 \%$ serum and the MPC pre-treatment was completed after $30 \mathrm{~min}$ of normal culture. Cells then received the same treatment as the H/R group.

Cell transfection. Cells were cultured for $12-16$ h to $60-70 \%$ confluence, and then transfected with Lipofectamine ${ }^{\circledR} 3000$ (Thermo Fisher Scientific, Inc.) according to the manufacturer's protocol. miR-320-3p mimic (miR10000903-1-5; 5'-AAA
AGCUGGGUUGAGAGGGCGA-3'), mimic negative control (miRB160401025525-2-1; 5'-UUUGUACUACACAAAAGU ACUG-3'), and miR-320-3p inhibitor (miR20000903-1-5; 5'-UCGCCCUCUCAACCCGCUUUU-3'), and inhibitor negative control (miR2N0000001-1-5; 5'-CAGUACUUUUGUGUA GUACAAA-3') were purchased from Guangzhou RiboBio Co., Ltd. Briefly, when cells were at 60 to $70 \%$ confluence, the transfection was performed using Lipofectamine ${ }^{\circledR} 3000$ (Thermo Fisher Scientific, Inc.). miR-320-3p mimic, inhibitor, corresponding control and Lipofectamine ${ }^{\circledR}$ RNAiMAX (Thermo Fisher Scientific, Inc.) were diluted in Opti-MEM medium (Thermo Fisher Scientific, Inc.). Then, the diluted RNAs were added into the diluted Lipofectamine ${ }^{\circledR}$ reagent and incubated for $10 \mathrm{~min}$ at room temperature. The mixture containing the RNA was added to the cells. Following an 8-h incubation in the presence of transfection reagent, the medium was replaced, and the cells incubated for $2-4$ days at $37^{\circ} \mathrm{C}$ prior to subsequent experimentation.

Bioinformatics prediction. TargetScan7.2. (http://www. targetscan.org) was used for the biological prediction of miR-320-3p target genes.

Dual luciferase activity assay. The sequence of Akt3-3'-UTR was cloned into the pmirGLO luciferase vector (cat. no. E1330; Promega Corp.). H9c2 cells were transfected with miR-320-3p mimic to detect the binding of Akt 3 and miR-320-3p. Cells transfected with miR-320-3p mimic negative control were used as the blank group. The cell transfection was performed by transfected with Lipofectamine ${ }^{\circledR} 3000$ (Thermo Fisher Scientific, Inc.) according to the manufacturer's protocol. Luciferase activity was determined using the Double-Luciferase Reporter Assay kit (cat. no. FR201-01; TransGen Biotech) according to the manufacturer's protocol. Briefly, the cell culture medium was removed, and the cells were carefully washed twice in PBS, then added to $20 \mu \mathrm{l}$ $1 \mathrm{X}$ Cell Lysis Buffer from the kit. The cells were lysed for $10 \mathrm{~min}$ at room temperature and centrifuged at $12,000 \mathrm{x} \mathrm{g}$ for $10 \mathrm{~min}$ at $4^{\circ} \mathrm{C}$ to collect supernatant for later use. After centrifugation, $100 \mu$ l Luciferase Reaction Reagent was added to the tube at room temperature, and $20 \mu \mathrm{l}$ cell lysate was carefully pipetted into the tube and mixed gently to measure the activity of the firefly luciferase reporter gene in a luminometer (SpectraMaxL, Molecular Devices, LLC). Finally, $100 \mu 1$ Luciferase Reaction Reagent II was added to the above reaction tube at room temperature, vortexed, and the activity of the Renilla luciferase reporter gene was detected using a SpectraMaxL luminometer (Molecular Devices, LLC).

Reverse transcription-quantitative PCR (RT-qPCR). Total RNA extraction from lysed $\mathrm{H} 9 \mathrm{c} 2$ cells was carried out at $4^{\circ} \mathrm{C}$ using TRIzol ${ }^{\circledR}$ (Invitrogen; Thermo Fisher Scientific, Inc.), and all the consumables and reagents used in the extraction process were subjected to DEPC treatment. The RT of miRNA and mRNA was conducted using TaqMan MicroRNA Reverse Transcription kit (cat. no. 4366597; Thermo Fisher Scientific, Inc.) and TaqMan Reverse Transcription Reagents (cat. no. N8080234; Thermo Fisher Scientific, Inc.). GAPDH served as internal control for mRNA, while U6 served as internal control for miRNA quantification. The primer sequences 
were as follows: miR-320-3p-forward (F), 5'-TAAGTGCTT CCATGTTTTGGTGA-3'; miR-320-3p-reverse (R), 5'-GAA CATGTCTGCGTATCTCAGACTTC-3'; Akt3-F, 5'-TCCCCC GAACACTCTCTTCA-3'; Akt3-R, 5'-CCCTCCACCAAG GCGTTTAT-3'; GAPDH-F, 5'-ATGACTCTACCCACGGCA AG-3'; GAPDH-R, 5'-GGAAGATGGTGATGGGTTTC-3'; U6-F, 5'-CTCGCTTCGGCAGCACA-3'; U6-R, 5'-AACGCT TCACGAATTTGCGT-3'. RT-qPCR was performed using the ABI7500 Real-Time PCR System (Thermo Fisher Scientific, Inc.) according to the manufacturer's instructions. The thermocycling conditions were set as follows: Initial denaturation at $95^{\circ} \mathrm{C}$ for $10 \mathrm{~min}$, followed by 45 cycles at $95^{\circ} \mathrm{C}$ for $30 \mathrm{sec}$, $59^{\circ} \mathrm{C}$ for $1 \mathrm{~min}$, and finally at $60^{\circ} \mathrm{C}$ for $1 \mathrm{~min}$, and preservation at $4^{\circ} \mathrm{C}$. The relative expression levels were calculated using the $2^{-\Delta \Delta \mathrm{Cq}}$ method (29).

MTT assay. Cell viability was detected using 3-(4,5-dimethylthiazol-2-yl)-2,5-diphenyltetrazolium bromide (cat. no. M6494; Thermo Fisher Scientific, Inc.). H9c2 cells were seeded in 96-well plates at a density of $5 \times 10^{4} / \mathrm{ml}$ and incubated for 24,48 and $72 \mathrm{~h}$ at $37^{\circ} \mathrm{C}$. A volume of $10 \mu 1$ MTT reagent was added into each well and cells were then cultured for an additional $4 \mathrm{~h}$ at $37^{\circ} \mathrm{C}$. After removing the MTT, $100 \mu \mathrm{l}$ DMSO was added. Finally, the optical density was measured at $490 \mathrm{~nm}$ using a microplate reader (cat. no. 24072800; Thermo Fisher Scientific, Inc.). Cells were seeded in triplicate wells and the experiment was repeated three times.

Lactate dehydrogenase ( $L D H)$ content determination. $\mathrm{LDH}$ content was measured using the Cytotoxicity LDH Assay Kit-WST (cat. no. CK12; Dojindo Molecular Technologies, Inc.), according to the manufacturer's protocol. Briefly, the cell suspension was diluted in $50 \mu \mathrm{l}$ medium, added to the 96-well plate with $50 \mu \mathrm{l}$ medium and incubated in a $\mathrm{CO}_{2}$ incubator at $37^{\circ} \mathrm{C}$ for $24 \mathrm{~h}$. A volume of $10 \mu \mathrm{l}$ Lysis Buffer was added into the control well and the reaction was incubated at $37^{\circ} \mathrm{C}$ with $5 \% \mathrm{CO}_{2}$ for $30 \mathrm{~min}$. After adding $100 \mu \mathrm{l}$ Working Solution into each well, the cells were incubated in the dark at room temperature for $30 \mathrm{~min}$. Next, $50 \mu \mathrm{l}$ Stop Solution was added to terminate the reaction, and the absorbance at $490 \mathrm{~nm}$ was determined immediately using a microplate reader (cat. no. 24072800; Thermo Fisher Scientific, Inc.).

Flow cytometry. A total of $1 \times 10^{6} \mathrm{H} 9 \mathrm{c} 2$ cells were harvested then centrifuged at $1,200 \mathrm{x}$ g for $1 \mathrm{~min}$ at $4^{\circ} \mathrm{C}$, then resuspended in $300 \mu \mathrm{l}$ pre-chilled PBS containing $10 \%$ calf serum. Cells were then fixed in $700 \mu \mathrm{l}$ absolute ethanol at $-20^{\circ} \mathrm{C}$ for $>24 \mathrm{~h}$, and centrifuged at $140 \mathrm{x}$ g for $30 \mathrm{sec}$ at $4^{\circ} \mathrm{C}$. Fixed cells were resuspended in $500 \mu \mathrm{l}$ cold PBS, and centrifuged at $1,200 \mathrm{xg}$ for $1 \mathrm{~min}$ at $4^{\circ} \mathrm{C}$. After discarding the supernatant, the pelleted cells were suspended in $480 \mu \mathrm{l}$ cold PBS and $10 \mu \mathrm{l}$ of $0.1 \mathrm{mg} / \mathrm{ml} \mathrm{RNase} \mathrm{A}$, and allowed to stand at $37^{\circ} \mathrm{C}$ for $30 \mathrm{~min}$. Annexin V-FITC and propidium iodide (PI) staining solution (5 $\mu \mathrm{l}$ each; cat. no. APOAF; Sigma-Aldrich; Merck KGaA) were added to the cell suspension for $15 \mathrm{~min}$ at room temperature in the dark. After the incubation, cells were filtered once through a 400-mesh sieve, and apoptosis was detected using a BD FACS Canto ${ }^{\mathrm{TM}}$ flow cytometer. Analysis was carried out using FlowJo version 10.0 (FlowJo, LLC). The lower left quadrant $\left(\mathrm{FITC}-\mathrm{H}^{-} / \mathrm{PI}\right)$ represents healthy living cells, while the lower right quadrant $\left(\mathrm{FITC}-\mathrm{H}^{+} / \mathrm{PI}^{-}\right)$represents early apoptotic cells. Late apoptotic cells are gated in the upper right quadrant $\left(\right.$ FITC- $\left.\mathrm{H}^{+} / \mathrm{PI}^{+}\right)$and necrotic cells are found in the upper left quadrant (FITC-H- $/ \mathrm{PI}^{+}$).

Western blot analysis. Total protein was extracted from H9c2 cells using RIPA buffer (cat. no. 89901; Thermo Fisher Scientific, Inc.) containing protease inhibitor and phosphatase inhibitor. The protein concentrations were measured using Pierce Rapid Gold BCA Protein Assay kit (cat. no. A53227; Thermo Fisher Scientific, Inc.). $30 \mu \mathrm{g}$ protein was separated by SDS-PAGE on $10 \%$ gels, then transferred to PVDF membranes (cat. no. HVLP04700; EMD Millipore). The films were fully rinsed in TBS, and then transferred to a dish containing 5\% skim milk solution and blocked at $37^{\circ} \mathrm{C}$ for $1 \mathrm{~h}$, then shaken for $2 \mathrm{~h}$ at room temperature on a decolorizing shaker. The membranes were then incubated with rabbit primary antibody against Akt3 (72 kDa; 1:2,000; cat. no. ab152157; Abcam) or mouse anti-GAPDH (36 kDa; 1:20,000; cat. no. ab8245; Abcam) overnight at $4^{\circ} \mathrm{C}$. The membrane was then incubated with an HRP-conjugated secondary antibody (1:5,000; cat. nos. ab205718 and ab205719; Abcam) for $2 \mathrm{~h}$ at room temperature. Finally, SignalFire electrochemiluminescence reagent (cat. no. 6883; Cell Signaling Technology, Inc.) was used for visualization. The ImageJ version 5.0 software (Bio-Rad Laboratories, Inc.) for quantification. GAPDH was used as the reference protein.

Statistical analysis. Data are presented as the mean \pm SD. Multi-group comparisons were conducted using one-way ANOVA, followed by Tukey's post hoc test. Statistical analysis was carried out using GraphPad Prism 7.0 (GraphPad Software, Inc.). $\mathrm{P}<0.05$ was considered to indicate a statistically significant difference. All experiments were performed in triplicate.

\section{Results}

$M P C$ protects rat cardiomyocytes from $H / R$ damage. To investigate the effects of MPC on reperfusion injury in rat cardiomyocytes, H9c2 cells were divided into Control, MPC, $\mathrm{H} / \mathrm{R}, \mathrm{MPC}+\mathrm{H} / \mathrm{R}$ groups. An MTT assay demonstrated that the viability of cells in the $\mathrm{H} / \mathrm{R}$ group was reduced, compared with the control. However, cell viability in the MPC+H/R group was significantly higher than that of the $\mathrm{H} / \mathrm{R}$ group $(\mathrm{P}<0.05$; Fig. $1 \mathrm{~A})$.

LDH levels indicate the number of dead and damaged cells. In the H/R group, the LDH content was increased, compared with the control. However, the LDH content in the MPC+H/R group was significantly lower than that in the H/R group ( $\mathrm{P}<0.05$; Fig. 1B). In addition, the levels of apoptosis were also examined in each of the four groups of cells. The frequency of apoptotic cells in the H/R group was increased, compared with control, but significantly decreased in the MPC+H/R group, compared with the $\mathrm{H} / \mathrm{R}$ group $(\mathrm{P}<0.05$; Fig. 1C).

$M P C$ regulates the expression of $m i R-320-3 p$ and Akt 3 . To further investigate the molecular mechanism of MPC in rat cardiomyocytes, RT-qPCR was performed to detect the expression of miR-320-3p. MPC treatment alone did not affect the expression of miR-320-3p. The expression of miR-320-3p in the $\mathrm{MPC}+\mathrm{H} / \mathrm{R}$ group was significantly lower than that in the $\mathrm{H} / \mathrm{R}$ group $(\mathrm{P}<0.05$; Fig. $2 \mathrm{~A})$. Moreover, the mRNA 
A

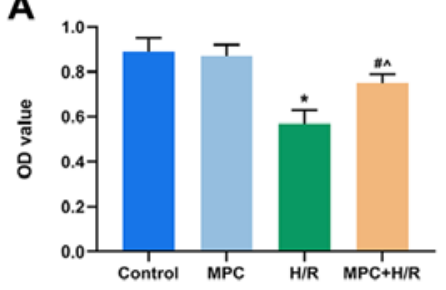

B

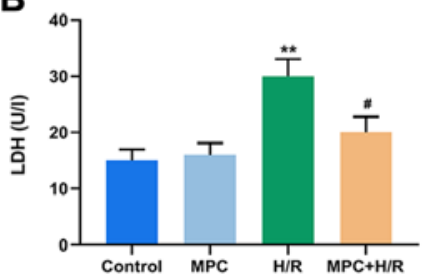

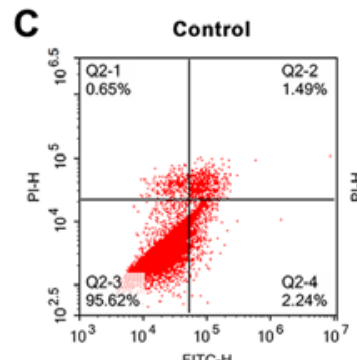
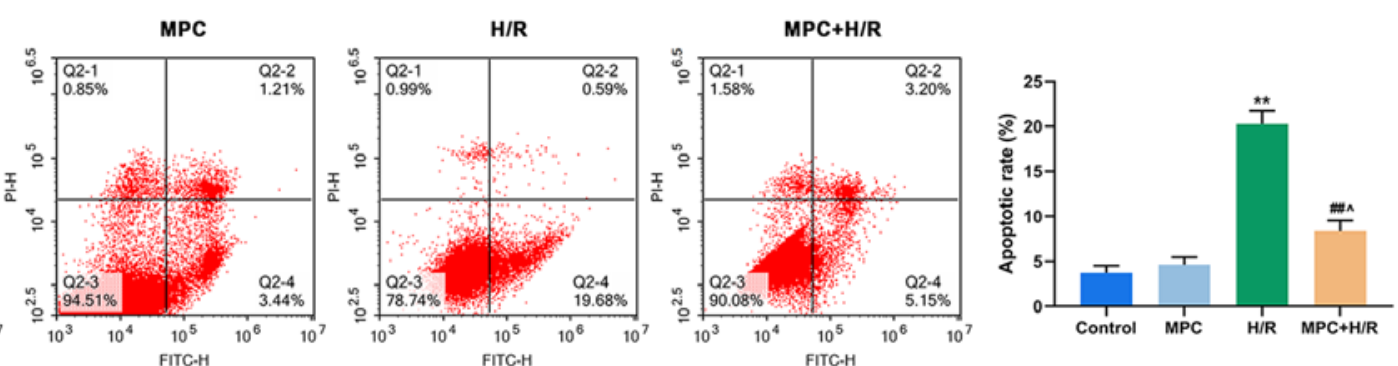

Figure 1. MPC protects rat cardiomyocytes from H/R damage. (A) MTT assay was used to assess the viability of H9c2 cells in the control, MPC, H/R and $\mathrm{MPC}+\mathrm{H} / \mathrm{R}$ groups. (B) Colorimetric assay was used to measure LDH levels in the control, MPC, H/R and MPC+H/R groups. (C) Flow cytometry was used to detect apoptosis in the control, MPC, H/R and MPC+H/R groups. ${ }^{*} \mathrm{P}<0.05$ and ${ }^{* *} \mathrm{P}<0.001$ vs. control; ${ }^{\#} \mathrm{P}<0.05$ and ${ }^{\# \#} \mathrm{P}<0.001$ vs. $\mathrm{H} / \mathrm{R}$; ${ }^{\wedge} \mathrm{P}<0.05$ vs. MPC group. MPC, morphine pre-conditioning; H/R, hypoxia/reoxygenation; LDH, lactate dehydrogenase; OD, optical density; PI, propidium iodide; FITC, fluorescein isothiocyanate.

A

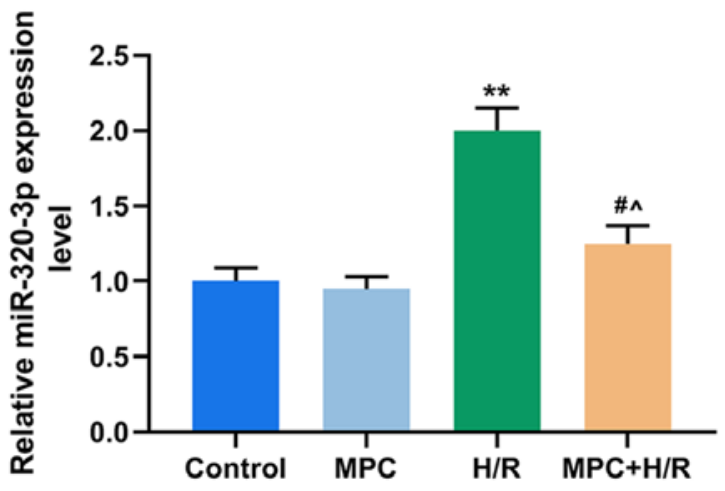

C

\section{Control MPC H/R MPC+H/R}

Akt3

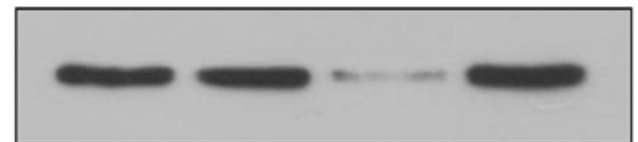

(72 kDa)

GAPDH

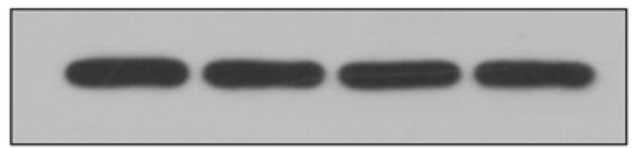

B
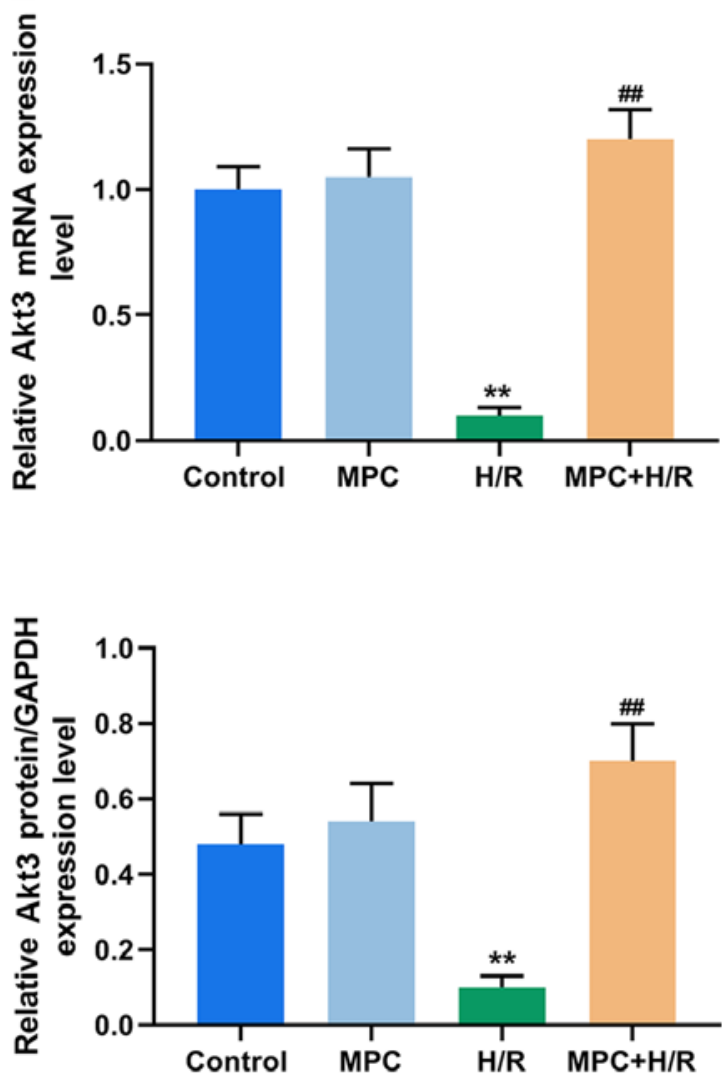

Figure 2. MPC regulates the expression of miR-320-3p and Akt3. (A) RT-qPCR was used to detect the miR-320-3p expression in the control, MPC, H/R and $\mathrm{MPC}+\mathrm{H} / \mathrm{R}$ groups. (B and C) RT-qPCR and western blot analysis were used to quantify Akt3 expression in the control, MPC, H/R and MPC+H/R groups. ${ }^{* *} \mathrm{P}<0.001$ vs. control; ${ }^{\#} \mathrm{P}<0.05$ and ${ }^{\# \#} \mathrm{P}<0.001$ vs. $\mathrm{H} / \mathrm{R} ;{ }^{\wedge} \mathrm{P}<0.05$ vs. MPC. MPC, morphine pre-conditioning; H/R, hypoxia/reoxygenation; miR, microRNA; RT-qPCR, reverse transcription-quantitative PCR.

and protein expression levels of Akt3 were also examined. MPC treatment alone did not affect the expression of Akt3. However, the expression of Akt3 in the H/R group was reduced, compared with the control. Additionally, expression of $\mathrm{Akt} 3$ in the $\mathrm{MPC}+\mathrm{H} / \mathrm{R}$ group was significantly higher than that in the $\mathrm{H} / \mathrm{R}$ group $(\mathrm{P}<0.05$; Fig. $2 \mathrm{~B}$ and $\mathrm{C})$. 
A

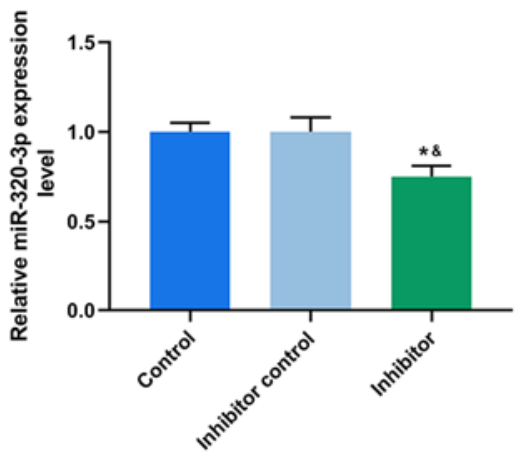

B

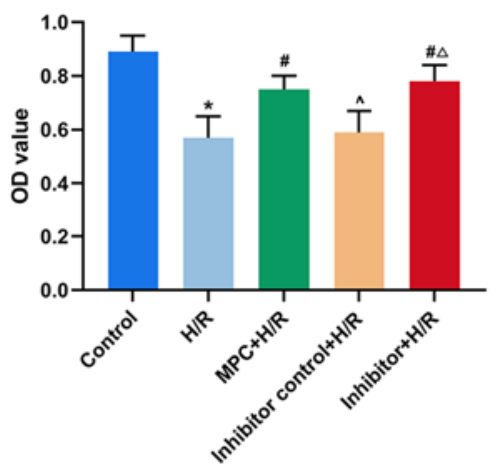

C

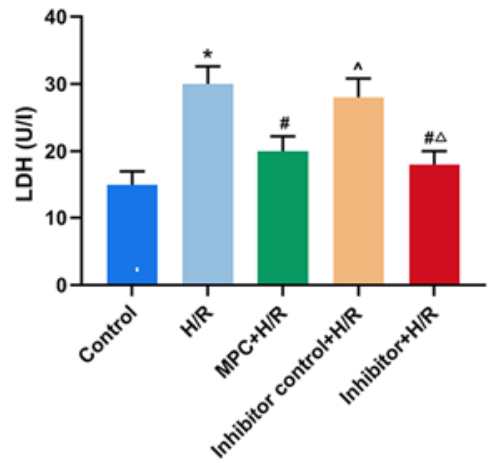

D

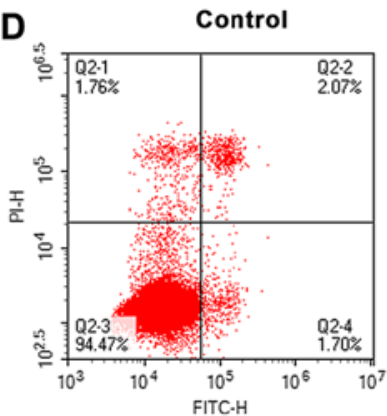

H/R

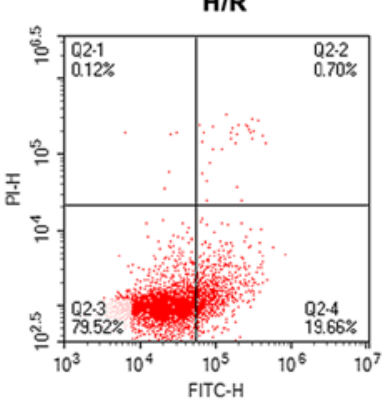

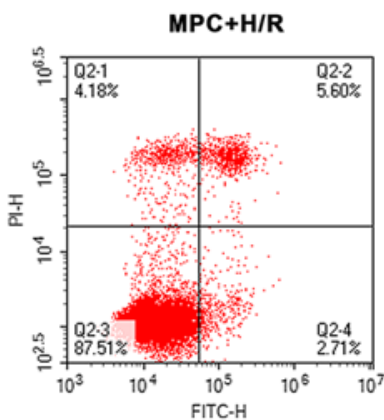
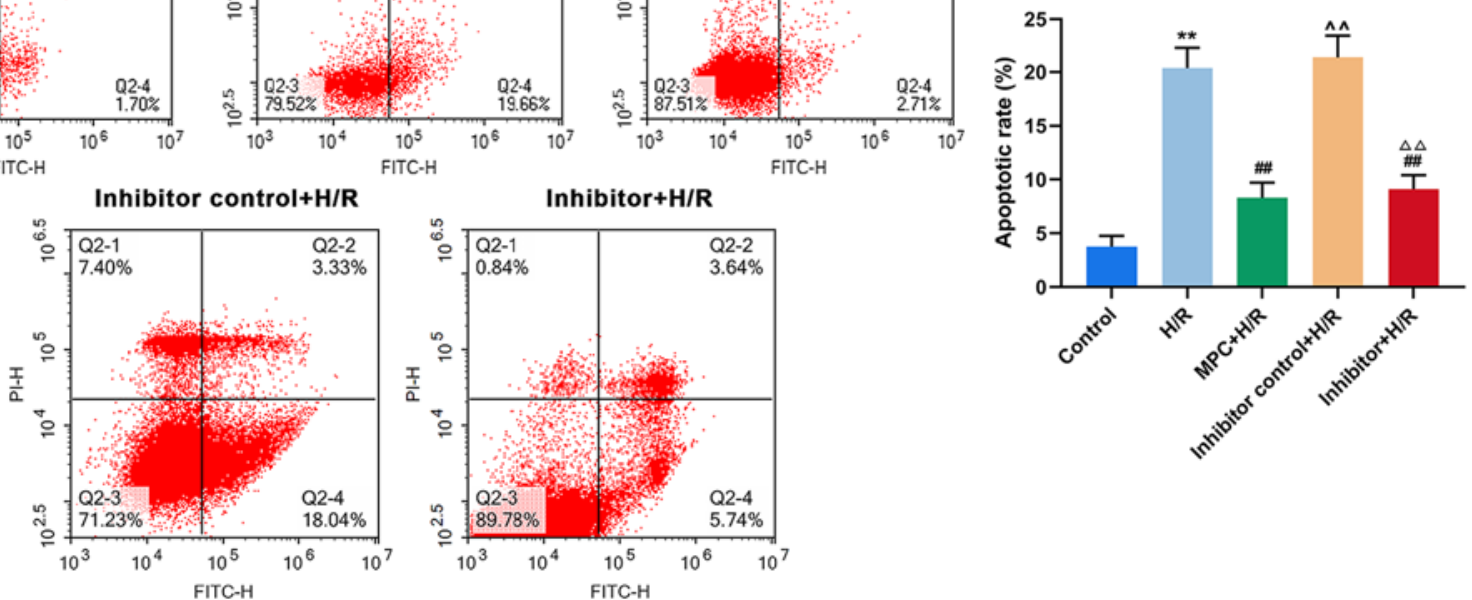

Figure 3. Downregulation of miR-320-3p attenuates H/R damage to cells. (A) Reverse transcription-quantitative PCR was used to determine the effect of miR-320-3p inhibitor transfection. (B) H9c2 cell viability in the control, H/R, MPC $+\mathrm{H} / \mathrm{R}$, inhibitor control+H/R and inhibitor+H/R groups using an MTT assay. (C) LDH content was measured in $\mathrm{H} 9 \mathrm{c} 2$ cells in the control, $\mathrm{H} / \mathrm{R}, \mathrm{MPC}+\mathrm{H} / \mathrm{R}$, inhibitor control+H/R and inhibitor+H/R groups using a colorimetric assay. (D) Apoptosis of H9c2 cells in the control, H/R, MPC+H/R, inhibitor control+H/R and inhibitor+H/R groups was detected using flow cytometry. ${ }^{\&} \mathrm{P}<0.05$ vs. Inhibitor control; ${ }^{*} \mathrm{P}<0.05$ and ${ }^{* *} \mathrm{P}<0.001$ vs. control; ${ }^{\#} \mathrm{P}<0.05$ and ${ }^{\# \#} \mathrm{P}<0.001$ vs. $\mathrm{H} / \mathrm{R} ;{ }^{\wedge} \mathrm{P}<0.05$ and ${ }^{\wedge} \mathrm{P}<0.001$ vs. $\mathrm{MPC}+\mathrm{H} / \mathrm{R} ;{ }^{\Delta} \mathrm{P}<0.05$ and ${ }^{\Delta \Delta} \mathrm{P}<0.001$ vs. Inhibitor control+H/R. MPC, morphine pre-conditioning; H/R, hypoxia/reoxygenation; miR, microRNA; LDH, lactate dehydrogenase; OD, optical density; PI, propidium iodide; FITC, fluorescein isothiocyanate.

Downregulation of $\mathrm{miR}-320-3 \mathrm{p}$ reduces $H / R$ damage to $H 9 c 2$ cells. To further understand the biological role of miR-320-3p in reperfusion injury of rat cardiomyocytes, $\mathrm{H} 9 \mathrm{c} 2$ cells were transfected with an miR-320-3p inhibitor (Fig. 3A). In the H/R group, an MTT assay demonstrated that the viability of cells transfected with the inhibitor (Inhibitor+H/R) was significantly higher than untransfected cells and was similar to the $\mathrm{MPC}+\mathrm{H} / \mathrm{R}$ group $(\mathrm{P}<0.05$; Fig. 3B). Furthermore, the LDH content in the Inhibitor $+\mathrm{H} / \mathrm{R}$ group was lower than that in the unstranfected $\mathrm{H} / \mathrm{R}$ group and was similar to the $\mathrm{MPC}+\mathrm{H} / \mathrm{R}$ group $(\mathrm{P}<0.05$; Fig. $3 \mathrm{C})$. As indicated by flow cytometry, the rates of apoptosis of in the Inhibitor $+\mathrm{H} / \mathrm{R}$ group was similar to that of the MPC+H/R group. However, this was significantly lower than that of the $H / R$ group $(\mathrm{P}<0.001$; Fig. 3D).

Upregulation of miR-320-3p targeting Akt3 inhibits the protective effect of MPC on $\mathrm{H} 9 \mathrm{c} 2$ cells. Using TargetScan v7.2 bioinformatics analysis and luciferase assay, Akt3 was identified as the direct target of miR-320-3p (Fig. 4A and B). Both at the mRNA and protein levels, the expression of Akt3 was significantly reduced in the untransfected cells of the H/R group, compared with control. However, Akt3 expression in the H/R-treated cells transfected with the inhibitor was significantly higher, compared to the untransfected cells $(\mathrm{P}<0.001$; Fig. 4C and D).

To better understand the effects of MPC, miR-320-3p and Akt 3 on reperfusion injury of rat cardiomyocytes, H9c2 cells were transfected with an miR-320-3p mimic (Fig. 5A). The expression of Akt3 in transfected cells of the MPC $+\mathrm{H} / \mathrm{R}$ group (Mimic+MPC+H/R group) was significantly lower than that in the untransfected MPC+H/R group ( $\mathrm{P}<0.05$; Fig. 5B and $\mathrm{C}$ ). Moreover, an MTT assay suggested that cell viability in the Mimic $+\mathrm{MPC}+\mathrm{H} / \mathrm{R}$ group was significantly lower than that in the MPC+H/R group ( $\mathrm{P}<0.05$; Fig. 5D). To further assess the 
A
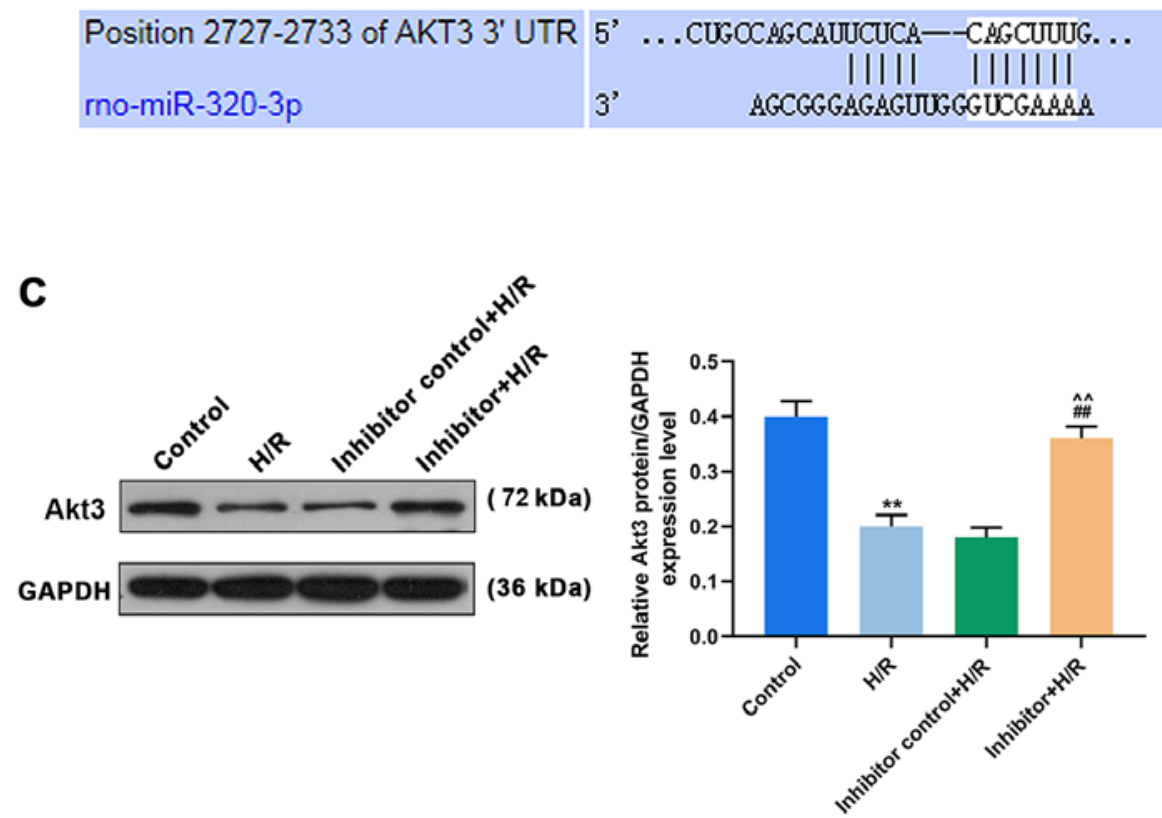

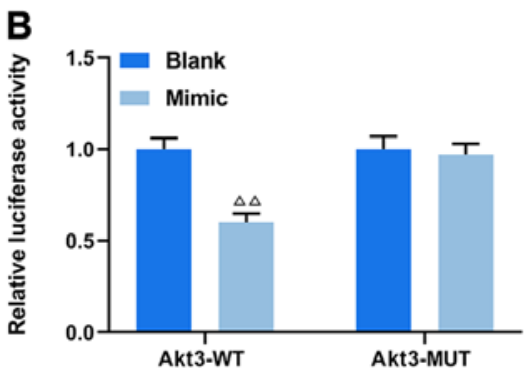

D

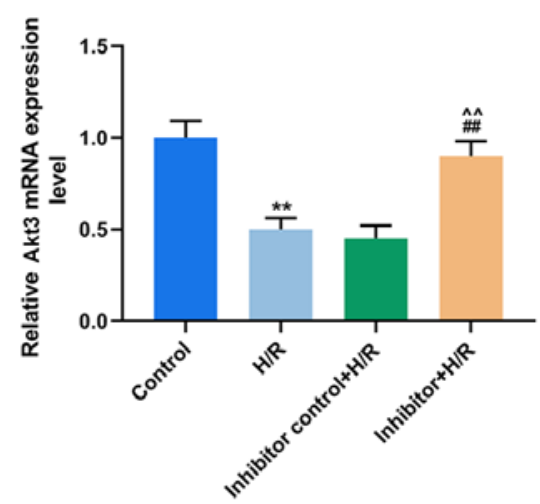

Figure 4. miR-320-3p directly regulates Akt3. (A) TargetScan v7.2 and (B) dual luciferase assay were used to identify the binding sites of miR-320-3p. (C) Reverse transcription-quantitative PCR and (D) western blot analysis were used to quantify Akt 3 expression in the control, H/R, inhibitor control+H/R and

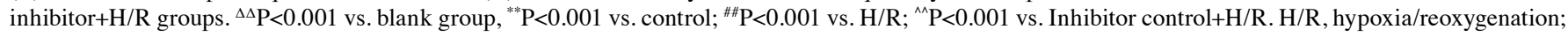
miR, microRNA; WT, wild-type; MUT, mutant.

biological function of miR-320-3p in H9c2 cells, LDH content was measured by colorimetry in each group. The LDH content of the Mimic+MPC+H/R group was significantly higher than that of the MPC $+\mathrm{H} / \mathrm{R}$ group $(\mathrm{P}<0.05$; Fig. $5 \mathrm{E})$. In addition, the rates of apoptosis in the Mimic $+\mathrm{MPC}+\mathrm{H} / \mathrm{R}$ group was significantly increased, compared with the $\mathrm{MPC}+\mathrm{H} / \mathrm{R}$ group $(\mathrm{P}<0.05$; Fig. 5F).

\section{Discussion}

Myocardial ischemia/reperfusion injury (MI/RI) is a pathophysiological process that occurs after revascularization in patients with ischemic heart disease, such as myocardial infarction $(30,31)$. Morphine is a non-selective opioid receptor agonist widely used as an anesthetic and in the treatment and myocardial infarction (32). Previous research has demonstrated that morphine has an early pre-conditioning effect on cardiomyocytes that is triggered by activation of opioid receptors (33). In the present study, the H9c2 cardiomyocyte hypoxia/reoxygenation injury model was established as previously described (34) but modified to incorporate $1 \mu \mathrm{M}$ morphine as pre-treatment (35). In the present study, MPC significantly enhanced the viability of cardiomyocytes, reduced the levels of LDH resulting from H/R injury, and inhibited the apoptosis of cardiomyocytes, indicating that MPC alleviates H/R injury and plays a role in myocardial protection.

miRNAs are abundantly expressed in cardiomyocytes and participate in pathophysiological processes, such as cardiomyocyte apoptosis, myocardial remodeling and heart failure (10). Several previous studies suggest that MI/RI could be alleviated through the upregulation or downregulation of the expression of target miRNAs, pointing to a new therapeutic target for clinical myocardial protection $(36,37)$. Yang et al (38) demonstrated that miRNA-22 can reduce apoptosis in MI/RI in a rat model by inhibiting CREB-binding protein expression and its downstream signaling pathway. Li et al (39) suggested that miRNA-145 expression was downregulated in an MI/RI model, whereas upregulation of miRNA-145 inhibited hydrogen peroxide-induced apoptosis, reactive oxygen species production, and activation of key signaling proteins in the mitochondrial apoptotic pathway. In addition, it has been reported that morphine can upregulate the expression of miR-133b-5p and protect cardiomyocytes from $\mathrm{H} / \mathrm{R}$ injury, indicating that the biological function of morphine may be achieved by regulating miRNA expression (9).

Previous studies indicate that the regulation of multiple signaling pathways could improve myocardial injury. For example, melatonin protects the diabetic heart against ischemia-reperfusion injury through membrane receptor-dependent activation of cyclic GMP-dependent guanosine monophosphate protein kinase (40). The inhibition of miR-101a-3p alleviates H/R injury in H9c2 cells by regulating the JAK2/STAT3 pathway (41). Downregulation of miR-134 protects against myocardial H/R injury through targeting nitric oxide synthase 3 and regulating the PI3K/Akt pathway (42). However, whether myocardial protection by MPC involves the regulation of miR-320-3p and PI3K/Akt signaling pathways is still unclear.

The present findings demonstrated that miR-320-3p expression was upregulated and Akt 3 expression was downregulated in cardiomyocytes after $\mathrm{H} / \mathrm{R}$ injury, while MPC partially reversed the changes in miR-320-3p and Akt3 
A

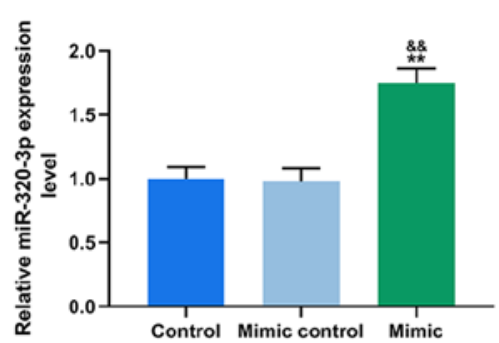

C

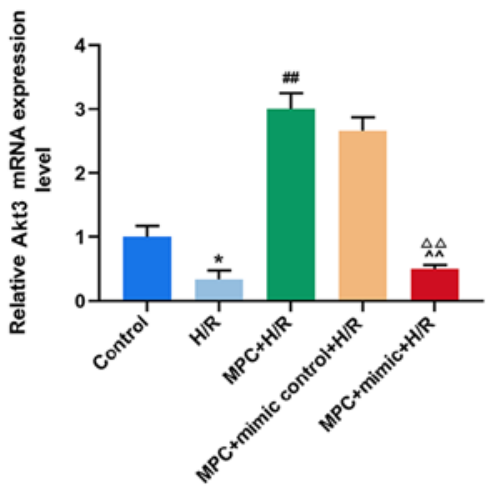

B

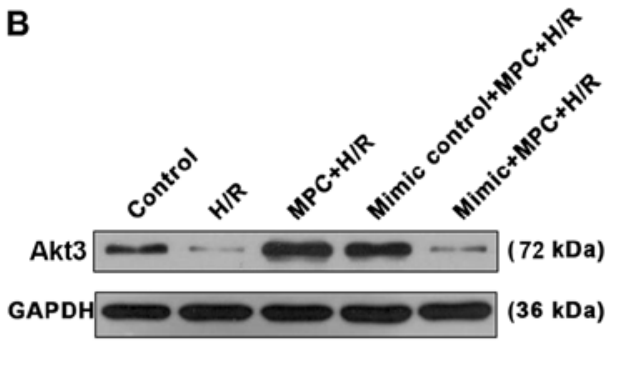

D

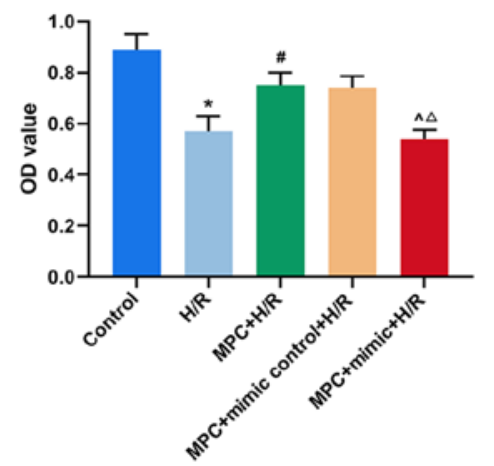

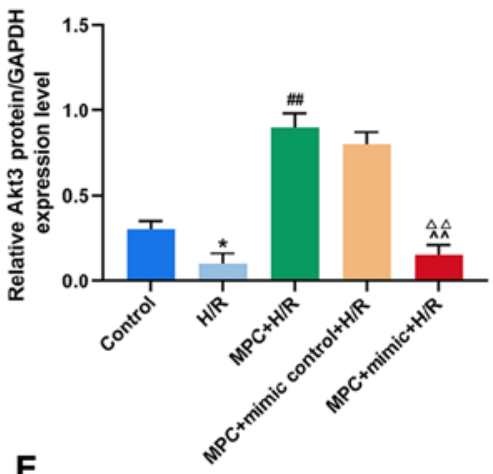

E

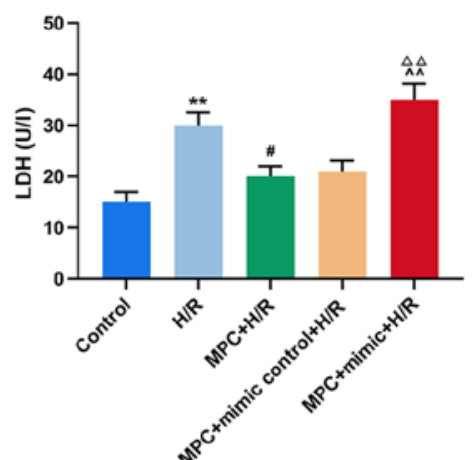

$\mathbf{F}$

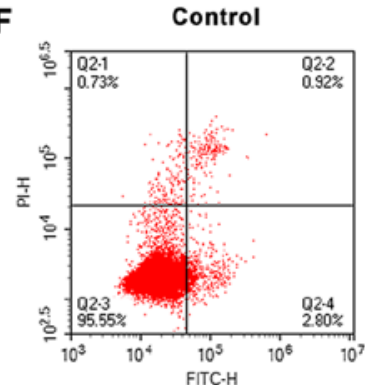

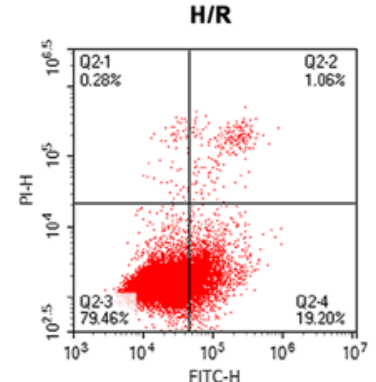

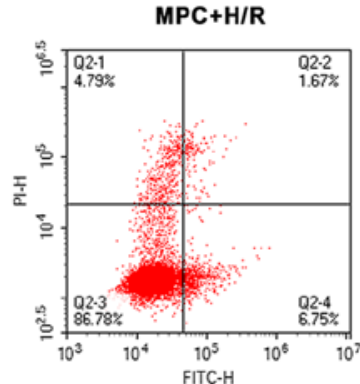

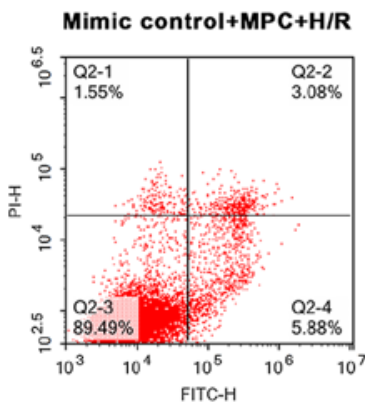
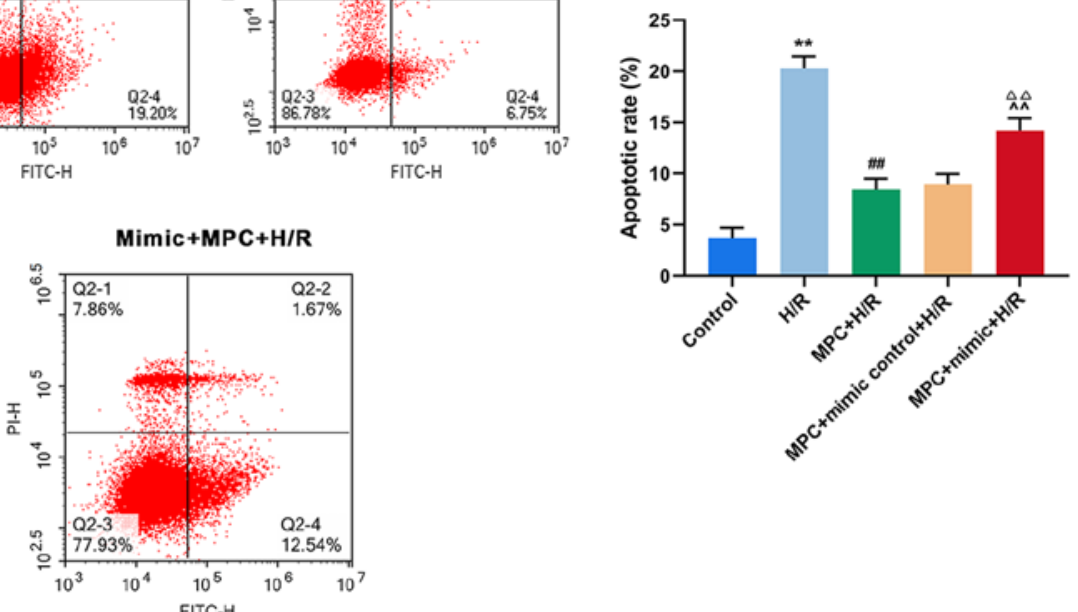

Figure 5. Upregulation of miR-320-3p targeting Akt3 inhibits the protective effect of MPC on H9c2 cells. (A) RT-qPCR was used to determine the effect of miR-320-3p mimic transfection. (B) RT-qPCR and (C) western blot analysis were used to detect Akt3 expression in the control, H/R, MPC+H/R, MPC+Mimic control+H/R and MPC+Mimic+H/R groups. (D) MTT assay was used to assess H9c2 cell viability in the control, H/R, MPC+H/R, MPC+Mimic control+H/R and MPC+Mimic+H/R groups. (E) LDH content was measured in the control, H/R, MPC+H/R, MPC+Mimic control+H/R and MPC+Mimic +H/R groups using a colorimetric assay. (F) Flow cytometry was used to detect the apoptosis of $\mathrm{H} 9 \mathrm{c} 2$ cells in the control, $\mathrm{H} / \mathrm{R}, \mathrm{MPC}+\mathrm{H} / \mathrm{R}, \mathrm{MPC}+\mathrm{Mimic}$ control $+\mathrm{H} / \mathrm{R}$ and $\mathrm{MPC}+\mathrm{Mimic}+\mathrm{H} / \mathrm{R}$ groups. ${ }^{\& \&} \mathrm{P}<0.001$ vs. mimic control, ${ }^{*} \mathrm{P}<0.05$ and ${ }^{* *} \mathrm{P}<0.001$ vs. control, ${ }^{\#} \mathrm{P}<0.05$ and ${ }^{\# \#} \mathrm{P}<0.001$ vs. $\mathrm{H} / \mathrm{R}$; ${ }^{\wedge} \mathrm{P}<0.05$ and ${ }^{\wedge \wedge} \mathrm{P}<0.001$ vs. MPC+H/R, ${ }^{\Delta} \mathrm{P}<0.05$ and ${ }^{\Delta \Delta} \mathrm{P}<0.001$ vs mimic control+MPC+H/R. MPC, morphine pre-conditioning; H/R, hypoxia/reoxygenation; miR, microRNA; RT-qPCR, reverse transcription-quantitative PCR; LDH, lactate dehydrogenase; OD, optical density; PI, propidium iodide; FITC, fluorescein isothiocyanate.

expression induced by the injury. This indicated that MPC plays an important role in the protection of $\mathrm{H} 9 \mathrm{c} 2$ cardiomyocytes by regulating miR-320-3p expression and the PI3K/Akt signaling pathway. Previous studies also demonstrated that miR-320 serves critical functions in many diseases such as glioma, ovarian cancer and osteosarcoma (16,43-46). 
Another study reported that miR-320 targeted A-kinase interacting protein 1 to induce mitochondrial apoptosis, and contributed to MI/RI (47). In the present study, the role of miR-320-3p in myocardial ischemia/reperfusion was further investigated using transfection of an miR-320-3p inhibitor, which indicated that inhibition of miR-320-3p expression enhanced cell viability, reduced LDH content and inhibited apoptosis. Moreover, these results were consistent with a previous study that suggested that miR-320-3p is involved in MI/RI (47).

In line with previous studies, it was hypothesized that downregulation of miR-320-3p may be involved in mediating MPC to protect myocardial cells from $H / R$ injury through the regulation of apoptosis. Through bioinformatics analysis and experimental validation, it was determined that miR-320-3p could directly interact with Akt3. The Akt3 gene encodes protein kinase $\mathrm{B}$ and plays an important role in the regulation of several physiological processes $(48,49)$. Transgenic mice display significant cardiac hypertrophy, suggesting that one of the functions of Akt3 is to promote cell growth (28). The PI3K/Akt signaling pathway is also involved in cardiac hypertrophy, myocardial cell remodeling and the prevention of inflammation, thereby alleviating myocardial ischemia-reperfusion injury (50-52). The present study suggested that overexpression of miR-320-3p inhibited the expression Akt3 following MPC, and reduced the protective effect of MPC on $\mathrm{H} / \mathrm{R}$ injury in cardiomyocytes. This indicated that MPC may protect cardiomyocytes from $\mathrm{H} / \mathrm{R}$ injury through inhibiting miR-320-3p expression and the PI3K/Akt signaling pathway.

In conclusion, the present study demonstrated that MPC could significantly reduce $\mathrm{H} / \mathrm{R}$ injury of $\mathrm{H} 9 \mathrm{c} 2$ cardiomyocytes, and its mechanism of action may be related to miR-320-3p and the PI3K/Akt3 signaling pathway. The present findings provide a basis for further research on miRNA regulation mechanism of morphine pre-treatment.

\section{Acknowledgements}

Not applicable.

\section{Funding}

No funding was received.

\section{Availability of data and materials}

The analyzed data sets used and/or analyzed during the current study are available from the corresponding author on reasonable request.

\section{Authors' contributions}

LC and SC made substantial contributions to conception and design. LC and SC acquired, analyzed and interpreted data. LC and SC drafted the article and critically revised the draft for important intellectual content. LC and SC agree to be accountable for all aspects of the work in ensuring that questions related to the accuracy or integrity of the work are appropriately investigated and resolved. All authors approved the final version of the manuscript.

\section{Ethics approval and consent to participate}

Not applicable.

\section{Patient consent for publication}

Not applicable.

\section{Competing interests}

The authors declare that they have no competing interests.

\section{References}

1. Frank A, Bonney M, Bonney S, Weitzel L, Koeppen M and Eckle T: Myocardial ischemia reperfusion injury: From basic science to clinical bedside. Semin Cardiothorac Vasc Anesth 16: 123-132, 2012.

2. Konstantinidis K, Whelan RS and Kitsis RN: Mechanisms of cell death in heart disease. Arterioscler Thromb Vasc Biol 32: 1552-1562, 2012.

3. Chen C, Jia KY, Zhang HL and Fu J: MiR-195 enhances cardiomyocyte apoptosis induced by hypoxia/reoxygenation injury via downregulating c-myb. Eur Rev Med Pharmacol Sci 20: 3410-3416, 2016.

4. Cao H, Xu H, Zhu G and Liu S: Isoquercetin ameliorated hypoxia/reoxygenation-induced $\mathrm{H} 9 \mathrm{C} 2$ cardiomyocyte apoptosis via a mitochondrial-dependent pathway. Biomed Pharmacother 95: 938-943, 2017.

5. McGilliard KL and Takemori AE: Alterations in the antagonism by naloxone of morphine-induced respiratory depression and analgesia after morphine pretreatment. J Pharmacol Exp Ther 207: 884-891, 1978.

6. Swartjes M, Mooren RA, Waxman AR, Arout C, van de Wetering K, den Hartigh J, Beijnen JH, Kest B and Dahan A: Morphine induces hyperalgesia without involvement of $\mu$-opioid receptor or morphine-3-glucuronide. Mol Med 18: 1320-1326, 2012.

7. Okubo S, Tanabe Y, Takeda K, Kitayama M, Kanemitsu S, Kukreja RC and Takekoshi N: Ischemic preconditioning and morphine attenuate myocardial apoptosis and infarction after ischemia-reperfusion in rabbits: Role of delta-opioid receptor. Am J Physiol Heart Circ Physiol 287: H1786-H1791, 2004.

8. Wang Y, Wang L, Li JH, Zhao HW and Zhang FZ: Morphine alleviates myocardial ischemia/reperfusion injury in rats by inhibiting TLR4/NF- $\mathrm{B}$ B signaling pathway. Eur Rev Med Pharmacol Sci 23: 8616-8624, 2019.

9. He SF, Zhu HJ, Han ZY, Wu H, Jin SY, Irwin MG and Zhang Y: MicroRNA-133b-5p is involved in cardioprotection of morphine preconditioning in rat cardiomyocytes by targeting fas. Can J Cardiol 32: 996-1007, 2016.

10. Bartel DP: MicroRNAs: Genomics, biogenesis, mechanism, and function. Cell 116: 281-297, 2004.

11. Whelan RS, Kaplinskiy V and Kitsis RN: Cell death in the pathogenesis of heart disease: Mechanisms and significance. Annu Rev Physiol 72: 19-44, 2010.

12. Hwang CK, Wagley Y, Law PY, Wei LN and Loh HH: MicroRNAs in opioid pharmacology. J Neuroimmune Pharmacol 7: 808-819, 2012.

13. Dong S, Cheng Y, Yang J, Li J, Liu X, Wang X, Wang D, Krall TJ, Delphin ES and Zhang C: MicroRNA expression signature and the role of microRNA-21 in the early phase of acute myocardial infarction. J Biol Chem 284: 29514-29525, 2009.

14. Cheng Y, Liu X, Zhang S, Lin Y, Yang J and Zhang C: MicroRNA-21 protects against the $\mathrm{H}(2) \mathrm{O}(2)$-induced injury on cardiac myocytes via its target gene PDCD4. J Mol Cell Cardiol 47: 5-14, 2009.

15. Ren XP, Wu J, Wang X, Sartor MA, Jones K, Qian J, Nicolaou P, Pritchard TJ and Fan GC: MicroRNA-320 is involved in the regulation of cardiac ischemia/reperfusion injury by targeting heat-shock protein 20. Circulation 119: 2357-2366, 2009.

16. Wu H, Li W, Zhang M, Zhu S, Zhang D and Wang X: Inhibitory roles of miR-320 in osteosarcoma via regulating E2F1. J Cancer Res Ther 12: S68-S71, 2016.

17. Wang W, Yang J, Xiang YY, Pi J and Bian J: Overexpression of hsa-miR-320 is associated with invasion and metastasis of ovarian cancer. J Cell Biochem 118: 3654-3661, 2017. 
18. Chen Q and Lesnefsky EJ: A new strategy to decrease cardiac injury in aged heart following ischaemia-reperfusion: Enhancement of the interaction between AMPK and SIRT1. Cardiovasc Res 114: 771-772, 2018.

19. Tian L, Cao W, Yue R, Yuan Y, Guo X, Qin D, Xing J and Wang X: Pretreatment with Tilianin improves mitochondrial energy metabolism and oxidative stress in rats with myocardial ischemia/reperfusion injury via AMPK/SIRT1/PGC-1 alpha signaling pathway. J Pharmacol Sci 139: 352-360, 2019.

20. Chen WR, Liu HB, Chen YD, Sha Y, Ma Q, Zhu PJ and Mu Y: Melatonin attenuates myocardial ischemia/reperfusion injury by inhibiting autophagy via an AMPK/mTOR signaling pathway. Cell Physiol Biochem 47: 2067-2076, 2018.

21. Liu L, Jin X, Hu CF, Li R, Zhou Z and Shen CX: Exosomes derived from mesenchymal stem cells rescue myocardial ischaemia/reperfusion injury by inducing cardiomyocyte autophagy Via AMPK and Akt pathways. Cell Physiol Biochem 43: 52-68, 2017

22. Kosuru R, Cai Y, Kandula V, Yan D, Wang C, Zheng H, Li Y, Irwin MG, Singh S and Xia Z: AMPK contributes to cardioprotective effects of pterostilbene against myocardial ischemia-reperfusion injury in diabetic rats by suppressing cardiac oxidative stress and apoptosis. Cell Physiol Biochem 46: 1381-1397, 2018

23. Gu C, Li T, Jiang S, Yang Z, Lv J, Yi W, Yang Y and Fang M: AMP-activated protein kinase sparks the fire of cardioprotection against myocardial ischemia and cardiac ageing. Ageing Res Rev 47: 168-175, 2018

24. Chen K, Li G, Geng F, Zhang Z, Li J, Yang M, Dong L and Gao F: Berberine reduces ischemia/reperfusion-induced myocardial apoptosis via activating AMPK and PI3K-Akt signaling in diabetic rats. Apoptosis 19: 946-957, 2014

25. Sun Y, Jiang C, Jiang J and Qiu L: Dexmedetomidine protects mice against myocardium ischaemic/reperfusion injury by activating an AMPK/PI3K/Akt/eNOS pathway. Clin Exp Pharmacol Physiol 44: 946-953, 2017.

26. Liu J, Huang W, Ren C, Wen Q, Liu W, Yang X, Wang L, Zhu B, Zeng L, Feng X, et al: Flotillin-2 promotes metastasis of nasopharyngeal carcinoma by activating NF- $\mathrm{KB}$ and PI3K/Akt3 signaling pathways. Sci Rep 5: 11614, 2015.

27. Zhou K, Fan YD, Wu PF, Duysenbi S, Feng ZH, Du GJ and Zhang TR: MicroRNA-145 inhibits the activation of the mTOR signaling pathway to suppress the proliferation and invasion of invasive pituitary adenoma cells by targeting AKT3 in vivo and in vitro. Onco Targets Ther 10: 1625-1635, 2017.

28. Khedr RM, Ahmed AAE, Kamel R and Raafat EM: Sitagliptin attenuates intestinal ischemia/reperfusion injury via cAMP/PKA, $\mathrm{PI} 3 \mathrm{~K} / \mathrm{Akt}$ pathway in a glucagon-like peptide 1 receptor-dependent manner. Life Sci 211: 31-39, 2018.

29. Livak KJ and Schmittgen TD: Analysis of relative gene expression data using real-time quantitative PCR and the 2(-Delta Delta C(T)) method. Methods 25: 402-408, 2001.

30. Tang H, Song X, Ling Y, Wang X, Yang P, Luo T and Chen A: Puerarin attenuates myocardial hypoxia/reoxygenation injury by inhibiting autophagy via the Akt signaling pathway. Mol Med Rep 15: 3747-3754, 2017.

31. Xiao R, Xiang AL, Pang HB and Liu KQ: Hyperoside protects against hypoxia/reoxygenation induced injury in cardiomyocytes by suppressing the Bnip3 expression. Gene 629: 86-91, 2017.

32. Coles JA Jr, Sigg DC and Iaizzo PA: Role of kappa-opioid receptor activation in pharmacological preconditioning of swine. Am J Physiol Heart Circ Physiol 284: H2091-H2099, 2003.

33. Peart JN, Patel HH and Gross GJ: Delta-opioid receptor activation mimics ischemic preconditioning in the canine heart. J Cardiovasc Pharmacol 42: 78-81, 2003.

34. Sun L, Zhao M, Yu XJ, Wang H, He X, Liu JK and Zang WJ: Cardioprotection by acetylcholine: A novel mechanism via mitochondrial biogenesis and function involving the PGC-1a pathway. J Cell Physiol 228: 1238-1248, 2013.

35. Liang BT and Gross GJ: Direct preconditioning of cardiac myocytes via opioid receptors and KATP channels. Circ Res 84 1396-1400, 1999.
36. Pan Z, Sun X, Ren J, Li X, Gao X, Lu C, Zhang Y, Sun H, Wang Y, Wang $\mathrm{H}$, et al: miR-1 exacerbates cardiac ischemia-reperfusion injury in mouse models. PLoS One 7: e50515, 2012.

37. Yang Y, Del Re DP, Nakano N, Sciarretta S, Zhai P, Park J, Sayed D, Shirakabe A, Matsushima S, Park Y, et al: miR-206 mediates YAP-induced cardiac hypertrophy and survival. Circ Res 117: 891-904, 2015.

38. Yang J, Chen L, Yang J, Ding J, Li S, Wu H, Zhang J, Fan Z, Dong W and Li X: MicroRNA-22 targeting CBP protects against myocardial ischemia-reperfusion injury through anti-apoptosis in rats. Mol Biol Rep 41: 555-561, 2014.

39. Li R, Yan G, Li Q, Sun H, Hu Y, Sun J and Xu B: MicroRNA-145 protects cardiomyocytes against hydrogen peroxide $\left(\mathrm{H}_{2} \mathrm{O}_{2}\right)$-induced apoptosis through targeting the mitochondria apoptotic pathway. PLoS One 7: e44907, 2012.

40. Yu LM, Di WC, Dong X, Li Z, Zhang Y, Xue XD, Xu YL, Zhang J, Xiao X, Han JS, et al: Melatonin protects diabetic heart against ischemia-reperfusion injury, role of membrane receptor-dependent cGMP-PKG activation. Biochim Biophys Acta Mol Basis Dis 1864: 563-578, 2018.

41. Liu J, Wang J, Ning Y and Chen F: The inhibition of miR-101a-3p alleviates $\mathrm{H} / \mathrm{R}$ injury in $\mathrm{H} 9 \mathrm{C} 2$ cells by regulating the JAK2/STAT3 pathway. Mol Med Rep 21: 89-96, 2020.

42. Xiao JM, Wang JJ and Sun LL: Effect of miR-134 against myocardial hypoxia/reoxygenation injury by directly targeting NOS3 and regulating PI3K/Akt pathway. Acta Cir Bras 34: e201900802, 2019.

43. Luo L, Yang R, Zhao S, Chen Y, Hong S, Wang K, Wang T, Cheng J, Zhang T and Chen D: Decreased miR-320 expression is associated with breast cancer progression, cell migration, and invasiveness via targeting Aquaporin 1. Acta Biochim Biophys Sin (Shanghai) 50: 473-480, 2018.

44. Pan C, Gao H, Zheng N, Gao Q, Si Y and Zhao Y: miR-320 inhibits the growth of glioma cells through downregulating PBX3. Biol Res 50: 31, 2017.

45. Zhang T, Zou P, Wang T, Xiang J, Cheng J, Chen D and Zhou J: Down-regulation of miR-320 associated with cancer progression and cell apoptosis via targeting Mcl-1 in cervical cancer. Tumour Biol 37: 8931-8940, 2016

46. Zhu H, Jiang X, Zhou X, Dong X, Xie K, Yang C, Jiang H, Sun X and Lu J: Neuropilin-1 regulated by miR-320 contributes to the growth and metastasis of cholangiocarcinoma cells. Liver Int 38: $125-135,2018$.

47. Tian ZQ, Jiang $\mathrm{H}$ and Lu ZB: miR-320 regulates cardiomyocyte apoptosis induced by ischemia-reperfusion injury by targeting AKIP1. Cell Mol Biol Lett 23: 41, 2018.

48. Alcantara D, Timms AE, Gripp K, Baker L, Park K, Collins S, Cheng C, Stewart F, Mehta SG, Saggar A, et al: Mutations of AKT3 are associated with a wide spectrum of developmental disorders including extreme megalencephaly. Brain 140: 2610-2622, 2017.

49. Chin YR, Yoshida T, Marusyk A, Beck AH, Polyak K and Toker A: Targeting Akt3 signaling in triple-negative breast cancer. Cancer Res 74: 964-973, 2014.

50. Carloni S, Girelli S, Buonocore G, Longini M and Balduini W: Simvastatin acutely reduces ischemic brain damage in the immature rat via Akt and CREB activation. Exp Neurol 220: 82-89, 2009.

51. Yao H, Han $X$ and Han $X$ : The cardioprotection of the insulin-mediated PI3K/Akt/mTOR signaling pathway. Am J Cardiovasc Drugs 14: 433-442, 2014.

52. Song HP, Chu ZG, Zhang DX, Dang YM and Zhang Q: PI3K-AKT pathway protects cardiomyocytes against hypoxia-induced apoptosis by MitoKATP-mediated mitochondrial translocation of pAKT. Cell Physiol Biochem 49: 717-727, 2018.

This work is licensed under a Creative Commons Attribution-NonCommercial-NoDerivatives 4.0 International (CC BY-NC-ND 4.0) License. 